\title{
THE TRICHOTOMY OF PROCESSES: A PHILOSOPHICAL BASIS FOR INFORMATION SYSTEMS
}

\author{
George R. Widmeyer \\ University of Michigan \\ School of Business Administration \\ 701 Tappan Street \\ Ann Arbor, MI 48109-1234 \\ USA \\ Phone: 1-734-763-5808 \\ Fax: 1-734-764-3146 \\ Email: widmeyer@umich.edu
}

\begin{abstract}
The principle of trichotomy from the American philosopher Charles S. Peirce can be used to categorize processes into the triad of transactional, relational, and informational. The usefulness of these categories is explicated by a comparison with structuration theory and control theory, and elaborated with a consideration of democracy in a knowledge economy. These three example applications of the process triad show the generality of the conceptual categories and provide a natural way of bringing ideas from social and ethical theories into information systems design. Modeling the world and understanding business applications through the use of the Trichotomy of Processes should facilitate the development of more valuable information systems.
\end{abstract}

Keywords: business processes, information systems theory, conceptual modeling, ontology, Peirce, open society

\section{INTRODUCTION}

Various frameworks for understanding the business processes of an organization have been proposed. There are linear, sequential models such as the Porter Value Chain (Porter 1980) or the Plan, Source, Make, Deliver, Return of the Supply Chain Operations Reference-model (SupplyChain Council 2000). There are cyclic models such as the Customer Service Life Cycle (Ives and Learmouth 1984) or the Knowledge Management Life Cycle (Birkinshaw and Sheehan 2002). Each of these models starts with an examination of the goods or services that are delivered to a customer of an organization and, as such, are mostly grounded in a view of the flow of physical entities in an organization.

This paper proposes an approach for information systems conceptual modeling based on a metalevel categorization of business processes. It uses the principle of Firstness, Secondness and Thirdness as developed by Charles S. Peirce (American Philosopher, 1839 - 1914) to generate a triad of categories for business processes, which is referred to in this paper as the Principle of Trichotomy. The resulting categories are identified as the Transactional, Relational, and Informational. Whereas Peirce developed his principle as a metalevel distinction for generating categories by viewing entities from different perspectives this paper uses it to generate a triad of business processes.

The rest of this paper is structured as follows. The next section describes Peirce's concept of Firstness, Secondness, and Thirdness and the Principle of Trichotomy. This is applied to processes with the result being the Trichotomy of Processes. Section three addresses social process from the perspective of the triads of Giddens (1993), Ouchi (1979), and Popper (1966). This is followed by the application of the process triads to e-business and virtual organizations. The final section is some conclusions and suggestions for future research.

\section{TRICHOTOMY OF CONCEPTS}

A fundamental concept in philosophy is ontology, which is the study of the categories of things that exist or may exist in some domain (Sowa 2000, p 492). This section uses Peirce's Principle of Trichotomy to generate a triad of categories for business processes. 


\section{Trichotomy}

The ancient Greeks, the Scholastics, and many other philosophical traditions categorized the nature of things. Immanuel Kant (1787) developed a table of categories in four groups of three. Kant believed that the triadic pattern was fundamental: "In every group, the number of categories is always the same, namely, three. That is remarkable because elsewhere all a priori division of concepts must be by dichotomy. Furthermore, the third category always arises from a combination of the second category with the first." (p B:110) The German philosophers continued this development. In particular, Hegel's (1831) development of a dialectical reasoning involved the triadic pattern of thesis, antithesis, and synthesis. Peirce was critical of Hegel's logic and at the same time he was intrigued by his triads of categories (Peirce 1998, p 428).

Peirce states in his Cambridge conference lectures of 1898 that he had been "a passionate devotee of Kant" but he also perceived "that there was something wrong with Kant's formal logic" (Peirce 1992, p 124). His own analysis led him to conclude that some, but not all of Kant's triads reflected more basic categories, which he called First, Second, and Third.

Three conceptions are perpetually turning up at every point in every theory of logic, and in the most rounded system they occur in connection with one another. They are conceptions so very broad and consequently indefinite that they are hard to seize and may be easily overlooked. I call them the conceptions of First, Second, Third. First is the conception of being or existing independent of anything else. Second is the conception of being relative to, the conception of reaction with, something else. Third is the conception of mediation, whereby a first and a second are brought into relation. (Peirce 1891, p 175)

There are two key features of his categories: First, Second, and Third are of equal status; and, it is not necessary to go beyond the three, because Fourth, Fifth, and higher-order relations can always be defined in terms of the three.

Peirce's principle can be used to generate differing perspectives for viewing entities (Sowa 2000). Firstness is the properties inherent in something. If $\mathrm{x}$ is a variable of type entity, then Firstness can be defined by the monadic predicate $\mathrm{P}(\mathrm{x})$, which describes the entity $\mathrm{x}$ by its property $\mathrm{P}$. Secondness is a relation or reaction between $\mathrm{x}$ and another entity $\mathrm{y}$, which is the dyadic relation $\mathrm{R}(\mathrm{x}$, y). Thirdness involves mediation between two entities by a third, which can be represented by the irreducible triadic relation $\mathrm{M}(\mathrm{x}, \mathrm{y}, \mathrm{z})$. Peirce emphasized that the Third could not be represented using two Seconds. Sowa (2000) uses the Principle of Trichotomy to generate his three primitive categories for entities of Independent, Relative and Mediating.

As an example of the Principle of Trichotomy consider the diagram in Figure 1 that would be common in a three-factor research model.

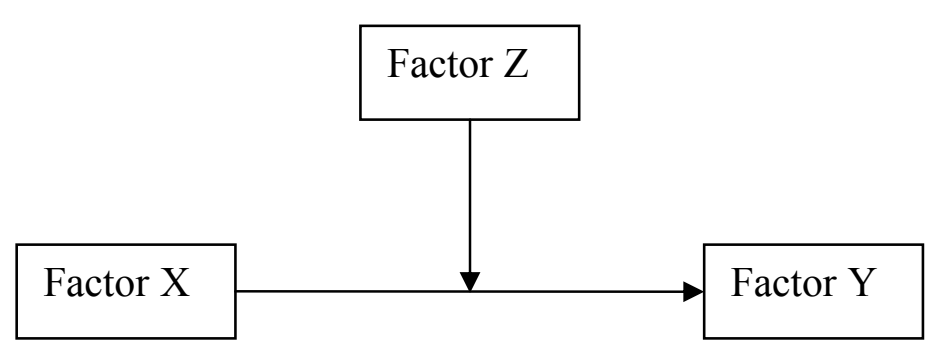

Figure 1. Example of a Three-Factor Research Model 
The properties of factor $X$ are Firstness and likewise for factors $Y$ and $Z$. The relationship between factor $\mathrm{X}$ and $\mathrm{Y}$ is Secondness. Factor $\mathrm{Z}$ mediates the relationship between $\mathrm{X}$ and $\mathrm{Y}$; and hence, the third order relationship is Thirdness. Note that $\mathrm{X}, \mathrm{Y}$ and $\mathrm{Z}$ are the entities, and the properties and relations are the Firstness, Secondness, and Thirdness.

Most readers who know of the work of Peirce are probably familiar with his three characteristics concerned with the functioning of a Sign - the Sign itself, its Object, and its Interpretant. Peirce started his development of a theory of signs, which he called Semeiotic, in 1867 and wrote many papers on it throughout his life (1906). His early ideas started with the trichotomy of icon, index, and symbol, but he later recognized that this relational trichotomy is based on Secondness- the relationship between a sign and its object (Sowa 2000, p 396). Given his belief in the Principle of Trichotomy he then developed trichotomies based on the Firstness and Thirdness of Signs (Peirce 1906). This approach could be pursued for processes, but I will adopt Peirce's phrasing to state that my conception on this "is not yet quite free from mist" (Peirce 1906, p 505) and hence this paper only presents a trichotomy (singular) for processes. A key idea from Peirce is that the same sign can be called an icon or an index or a symbol; that is, it can function in multiple ways. If this idea is applied to processes then it means that a specific business process can have some properties that are considered Firstness, and some Secondness, and some Thirdness.

\section{Trichotomy of Processes}

Most ontological studies consider the properties and relations of things or entities. A different view of what exists in the world takes processes as its fundamental concept. In the book Process and Reality, Whitehead (1929) develops a process-oriented ontology and eight categories of existence. These eight categories constitute two Peircean triads, supplemented with two extra categories for generating combinations (Sowa 2000). This paper adopts the process-oriented view and proposes the triad of Transactional, Relational, and Informational as presented in Table 1. The first row is from Peirce (1891), the second row is from Sowa (2000), and the third row is the result of applying the Principle of Trichotomy to processes.

\begin{tabular}{|l|l|l|}
\hline Firstness & Secondness & Thirdness \\
\hline Independent & Relative & Mediating \\
\hline Transactional & Relational & Informational \\
\hline
\end{tabular}

Table 1. Trichotomy of Processes

The Transactional category for processes contains the basic property of all processes. A process has a state and transitions between states are events (Arbib 1987). Transactions cause the transitions between states, and how faithfully or reliably those transitions occur is a characteristic of the processes. This is Firstness because it is a property of a process being or existing independent of any other processThe Relational category for processes represents the relationship of one process with another. This category captures the properties of the relationship between two processes. This relationship need not be symmetrical; that is, it may be viewed differently from one process versus the other. Also, it may specify a potential or possible non-negative mode of being between the processes. This is Secondness because there is a dyadic relation between each process and each process is viewed relative to the other.

The Informational category for processes captures the creation of a relationship between two other processes. The strength of the relationship between the two processes is mediated by the third. This irreducible triadic relation between three processes specifies a pragmatic or intentional understanding of a process and provides a context for interpreting the data exchanged between two processes. This is Thirdness since each of the three processes is necessary and the third mediates the relationship between the first two.

Consider the process of making a commitment. A possible property of the commitment process is its reliability, which is Firstness. It takes two people or organizations to make a commitment and each participant in the commitment needs to be able to observe and respond to the other, the contracting relationship is Secondness. Thirdness is the property of a process that mediates two other processes. We could take "working together" as this process, and the strength of commitment is shown by how well the two people or organizations work together in achieving a goal. 


\section{TRIADS IN SOCIAL PROCESSES}

Organizational research often uses dichotomies in the form of two-by-two frameworks. There are also three-factor or three-dimensional models but these are usually inductively developed from social or organizational experience rather than deductively from first principles. This section applies the philosophically- (ontologically-) grounded Trichotomy of Processes to two particular organizational frameworks and elaborates the concept through a consideration of democracy in a knowledge economy.

\section{Structuration Theory}

The structuration theory of Anthony Giddens (1993) provides a connection between human action and social structure. The work of DeSanctis and Poole (1994) and Orlikowski and Robey (1991) are examples where the concepts from Giddens are used in information systems research. This section of the paper maps Giddens' triad of structures to the Trichotomy of Processes.

The key principle in structuration theory is that of duality of structure- human action is enabled and constrained by structure, but structure is also the result of human action. This duality of structure can be understood as follows: agents communicate, exercise power, and sanction their own behavior and that of others; in doing so they produce and reproduce (with possible transformation) structures of signification, domination, and legitimation (Orlikowski and Robey 1991). This is a dynamic process and involves three modalities. The dimensions of social interaction can be represented as in Table 2.

\begin{tabular}{|l|l|l|l|}
\hline Process & Transactional & Relational & Informational \\
\hline Structure & Domination & Legitimation & Signification \\
\hline Modality & Facility & Norm & Interpretative scheme \\
\hline Interaction & Power & Morality & Communication \\
\hline
\end{tabular}

Table 2. Structuration Theory and the Trichotomy of Processes

The concepts on the first line are the categories for processes based on the Peirce analysis from the previous section. The triad of structure based on Giddens (1993) is listed in the second row. Note that the order of the entries has been changed from the usual way that they are listed in tables and the order in which they are discussed by Giddens (1993, p 129-30) and other authors based on his work. The concepts on the fourth line refer to the properties of interaction that occur between members of a community. Modality refers to the mediation of interaction and structure. The use of power in interaction involves the application of facilities whereby participants are able to generate outcomes through affecting the conduct of others. The moral constitution of interaction involves the application of norms. These norms are based are based on structures of legitimation. Finally, the communication of meaning in interaction involves the use of interpretative schemes. These are cognitive schemes that depend upon a shared understanding by a community.

Giddens (1993, p 130) states that "Just as communication, power and morality are integral elements of interaction, so signification, domination and legitimation are only analytically separable properties of structure." This is similar the Peircean constraint on his Principle of Trichotomy in that First, Second, and Third are of equal status and it is not possible to reduce a Third to a pair of Seconds. The duality of structure and process is evident in Table 2.

The transactional properties of a process are related to the ability or facility to change the state of the process. Structures of domination control the resources of the process and can bring about changes through the exercise of power without the influence of other processes. This is Firstness.

The relational category of a process is related to the use of norms in the exercise of authority. Structures of legitimation control the use of moral rules of the process. The morality of the interaction determines the type of relationship between processes by sanctioning their own behavior and that of others. This is Secondness.

The informational category of a process is related to the use of interpretative schemes in communication. Structures of signification control the semantic rules of the process. Information 
can be defined as an interpretation of data. The relationship between the process and the semantic rules provides the meaning to the participants in the communicative interaction. This is Thirdness.

The mapping of the triad of Structuration Theory of Giddens to those of the Trichotomy of Processes is consistent with Giddens' duality of process and structure. This mapping helps in the explication of the transactional, relational, and informational characteristics of processes. The next section repeats this approach using a framework for the three modes of control of Ouchi.

\section{The Social Prerequisites of Control}

The design of organizational control by Ouchi (1979) provides three control mechanisms: market, bureaucracy, and clan. He arranges the three modes of control along two dimensions: the informational requirements necessary to operationalize each control type, and the social underpinnings necessary to operate each control type.

The social requirements are a set of agreements between people which are necessary for a form of control to be employed. According to Ouchi (1979, p 838) a market cannot exist without a norm of reciprocity that assures that if one party in a market transaction attempts to cheat another, then the cheater, if discovered, is punished by all members of the social system. He goes on to state that a bureaucracy contains not only a norm of reciprocity, but also agreement on legitimate authority. Finally, the clan form requires not only a norm of reciprocity and the idea of legitimate authority, but also social agreements on a broad range of values and beliefs.

"In reality, of course, we will never observe a pure market, pure bureaucracy, or a pure clan. Real organizations will each contain some features of each of the modes of control" (Ouchi 1979, p 840). Therefore, this paper just maps the social prerequisites of control to the Trichotomy of Processes as shown in Table 3.

\begin{tabular}{|l|l|l|l|}
\hline Process & Transactional & Relational & Informational \\
\hline Social Requirements & Legitimate Authority & Norm of Reciprocity & $\begin{array}{l}\text { Shared Values and } \\
\text { Beliefs }\end{array}$ \\
\hline
\end{tabular}

Table 3. Social Prerequisites of Control and the Trichotomy of Processes

The transactional properties of a process are related to the exercise of legitimate authority that is recognized as the right of higher organizational roles to command and to audit or monitor those holding lower organizational roles, within some limits. The relational properties are based on norms of reciprocity that require information for their exercise. Finally, the depth of the level of common agreement on values and beliefs mediates the strength of the relationship between processes. These three social prerequisites are parallel to the structures of Giddens described in the previous section.

\section{The Open Society}

The consideration of the role of democracy in a knowledge economy can lead to an appreciation of Karl Popper's (1966) concept of the open society. The Open Society and its Enemies by Karl Popper was written during "the grave years" of 1938 to 1943 "when the outcome of the war was uncertain" (Popper 1966, p viii). He provides a critical view of the philosophy of politics and of history with volume one having Plato and volume two having Hegel as "enemies" of the open society. "The magical or tribal or collectivist society will also be called the closed society, and the society in which individuals are confronted with personal decisions, the open society" (Popper 1966, $\mathrm{p}$ 173). As an example of characteristics of the open society he quotes Pericles' ideal of democracy.

Our administration favors the many instead of the few: this is why it is called a democracy. The laws afford equal justice to all alike in their private disputes, but we do not ignore the claims of excellence.

... We consider a man who takes no interest in the state not as harmless, but as useless; and although only a few may originate 
a policy, we are all able to judge it. [Emphasis in Popper]

(Popper 1966, p 186)

The idea of an open society can be founded on the concepts of fallibility, reciprocity, and the diversity of values, which conform to the Peircean triad of Firstness, Secondness, and Thirdness.

We want our processes to be reliable, but we must accept that they are fallible. Much conceptual effort is devoted to the design of business transactions that are reliable. If a business transaction fails then the process is generally designed to "rollback" to a previous state, but social transactions cannot be so easily rolled back. Social organizations fall short of perfection and must be designed on processes that are always held open for improvement. A key property of these processes then must be fallibility, which is Firstness.

This concept of business transactions as having the property of fallibility is consistent with Popper's concept of falsification in science (Popper 1989). It simply means that we can err in our choice or fall short of the truth. This does not mean that our process are irrational, only that we cannot be certain. He states that we should consider that "... all the known historical examples of human fallibility - including all the known examples of miscarriage of justice-are examples of the advance of our knowledge (Popper 1966, p 375-6). Our consideration of democracy in a knowledge economy should include the condition of fallibility in our processes, but this recognition of fallibility is a necessary but not sufficient condition. We must combine it with some degree of concern for our fellow human beings based on the norm of reciprocity (Soros 1998).

The relational category of business processes involves monitoring and reciprocity. If we go back to Ouchi's social prerequisites of control described in an earlier section, then we see that norms of reciprocity require data for their exercise. There must be a category of processes that includes these types of processes. At the same time, information is an interpretation of data, which means that it has a subjective nature that is partially determined by the social context of the process.

The informational category of business processes depends on values and beliefs that mediate the strength of the relationship between processes. Whereas Ouchi (1979) describes these as "shared values and beliefs," I use the phrase "diversity of values" that I think is more in line with Popper's open society concept. Certainly, shared values hold a society together, but acceptance of a diversity of values keep a society open to improvement (Soros 1998). The strength of the relational nature of our processes is mediated by the diversity of values and these provide a context for understanding social interactions.

The consideration of democracy in a knowledge economy can be framed in terms of the concept of the open society or organization. Information systems enable the business processes of an organization and this paper proposes that these should be categorized into transactional, relational, and informational. The Trichotomy of Processes provides the categories of different settings in which democratic principles can be explored, but rather than continue the next section focuses on business domain modeling to support the development of information systems.

\section{APPLICATION TO INFORMATION SYSTEMS}

Information technology enables process improvement, but many people can only think of ways to automate business processes. If they would also think of the relational and informational aspects of business process then they would have a much richer view of the value of information technology. This section describes two application areas in business that can benefit from the conceptual foundation provided by a Trichotomy of Processes.

\section{Electronic Marketplaces on the Internet}

Markets play an important role in both the traditional economy and the new economy, which is characterized by electronic networks and knowledge workers. The markets do not require a physical location and participants can be located globally and yet interact (almost) simultaneously.

Consider the functions of an auction-based market system (Bakos 1998). There needs to be systems of communications to match buyers and sellers, which are based on shared interpretative schemes for product representation and pricing. There needs to be systems of workflow to facilitate the 
transactions. These support the fulfillment processes of an exchange of property rights between participants. The relative power of the participants in the market system generally determines the design of the workflow processes. Finally, there needs to be systems of authority to provide the institutional infrastructure, which legitimates the efforts of the actors and supports dispute resolution. These functions can be related to the three C's of electronic commerce: content, commerce, and community. These relationships are summarized in the Table 4.

\begin{tabular}{|l|l|l|l|}
\hline Process & Transactional & Relational & Informational \\
\hline $\begin{array}{l}\text { Market } \\
\text { Functions }\end{array}$ & $\begin{array}{l}\text { Facilitation of } \\
\text { transactions }\end{array}$ & Institutional Infrastructure & $\begin{array}{l}\text { Matching buyers and } \\
\text { sellers }\end{array}$ \\
\hline E-commerce & Commerce & Community & Content \\
\hline
\end{tabular}

Table 4. Electronic Markets and the Trichotomy of Processes

The transactional properties of market processes are related to the facilitation of the transaction. The acceptance of community norms determines the interaction between participants. The institutional infrastructure relates the participants and this Secondness cannot be eliminated from the market without it ceasing to function. The informational relationship depends on the content of the process. Information is needed about both the buyers and the sellers in order to do the matching and the understanding of the content mediates the strength of the relationship between the buyers and sellers.

\section{Virtual Organizations}

The Trichotomy of Processes provides a starting framework for conceptualizing information systems that support a virtual organization. Most recent literature identifies the two general perspectives of structure and process in describing the characteristics of a virtual organization, but generally the process view focuses on the process of change (Saabeel, Verduijn, Hagdorn, and Kumar 2002). An alternative view is to start with the fundamental transactional, relational, and informational processes of any organization and then ask how these are different in a virtual organization.

The word "virtual" as an adjective means having the function but not the form. A virtual organization performs the function and has the processes of a non-virtual organization, but the form (structure) is different. The result should be evident in the behavior of the organization. Any set of processes generated by the Trichotomy of Processes principle should be evident in both types of organizations. My conjecture is that the information systems designed to support such processes are basically the same in both the virtual and non-virtual organizations. What may be different to those companies that compete most vigorously in a knowledge economy is the relative emphasis on the three types of processes, but this emphasis should depend less upon the virtualness of the organization and more on the knowledge intensity of the processes.

\section{Research Contribution}

Triads of categories are evident in many of the groundings that have been used in information systems research. This paper explores how these can be unified through a philosophical foundation for information systems. It specifically uses just one concept from the work of Charles S. Peirce; albeit, a concept that he considered fundamental to most of his philosophical thinking. Any "philosophy of information technology" needs to include ontology, and the Trichotomy of Processes provides a starting point.

A second contribution of this paper is that it uses the Principle of Trichotomy to generate a framework that unifies an understanding of organizational communication and information systems. The triad of Transactional, Relational, and Informational provides a framework for viewing the Giddens' (1993) triad of Structuration Theory: Domination, Legitimation, and Signification. It provides a view of Ouchi's (1979) triad of the Social Requirements of Control: Legitimate Authority, Norms of Reciprocity, and Shared Values / Beliefs. A third example of the proposed process triad is to the three C's of e-commerce: Commerce, Community and Content. These three example applications of the process triad show the generality of the conceptual categories and 
provide a natural way of bringing ideas from social and ethical theories into information systems design.

Finally, a practical contribution of the Trichotomy of Processes is that it can provide principles for business process improvement. The Trichotomy is useful in thinking about IT-enabled knowledge work. Consider the processes that need to be supported by a web-based portal for an organization. As a first principle - the design of the portal needs to provide services for transactional, relational, and informational processes. As a second principle - the design of the portal needs to support fallibility in the transactional processes, reciprocity in the relational processes, and diversity of values in the informational processes. These principles build on the argument presented in this paper, but they need to be tested in practice; even so, it is hypothesized that starting information systems design from these two principles should facilitate the development of more valuable information systems.

\section{CONCLUSIONS}

This paper lays a foundation for information systems conceptual modeling based on a categorization of processes into the triad of transactional, relational, and informational. The paper is conceptual in that it describes the three categories of processes and explicates them using Giddens' (1993) structuration theory, Ouchi's (1979) social prerequisites of control, and Popper's (1966) concept of the open society. The categories of processes can be applied to the design of information systems such as e-business applications or in the design of applications to support virtual organizations.

Stakeholders must be able to classify phenomena in the modeled domain and the generic concept of process could be refined with the Trichotomy of Processes. This can make it easier for stakeholders to model and understand the domain for the purpose of information systems development. The extensions to current conceptual modeling grammars and the development of new methods can both benefit from the ontological considerations presented in this paper.

The limitations of this current research is that it is conceptual and does not propose actual constructs for a grammar or how to extend current grammars such as data flow diagrams (DFD) or entityrelationship diagrams (ERD). Another area of future research could be directed to the development of new methods of using a current conceptual modeling grammar (Wand and Weber 2002) that is informed by the Trichotomy of Processes.

\section{REFERENCES}

Arbib, M. A. (1987) Brains, Machines, and Mathematics, 2nd edition, Springer-Verlag, New York.

Bakos, Y. (1998) "The emerging role of electronic marketplaces on the Internet," Communications of the ACM (41:8), pp 35-42.

Birkinshaw, J., and Sheehan, T. (2002) "Managing the knowledge life cycle," MIT Sloan Management Review (44:1), pp 75-83.

DeSanctis, G., and Poole, M.S. (1994) "Capturing the complexity of advanced technology use: Adaptive structuration theory," Organization Science (5:2), pp 121-147.

Giddens, A. (1993) New Rules Of Sociological Method: A Positive Critique Of Interpretative Sociologies, 2nd ed., Stanford University Press, Stanford, California.

Hegel, G. W. F. (1831) Science of Logic, translated by A. V. Miller, Humanities Press International, Atlantic Highlands, New Jersey, 1989.

Ives, B., and Learmonth, G. P. (1984) "The information system as a competitive weapon," Communications of the ACM (27:12), pp 1193-1201.

Kant, I. (1787) Critique of Pure Reason, edited P. Guyer \& A. W. Wood, Cambridge University Press, Cambridge, England, 1998.

Orlikowski, W.J., \& Robey, D. (1991) "Information technology and the structuring of organizations," Information Systems Research (2:2), pp 143-169.

Ouchi, W. G. (1979) "A conceptual framework for the design of organizational control mechanisms," Management Science (25:9), pp 833-848.

Peirce, C. S. (1891) “The Architecture of Theories,” Monist (I: 2), pp 161-176. 
Peirce, C. S. (1906) "Prolegomena to an Apology for Pragmaticism," Monist (XVI: 4), pp 492-546.

Peirce, C. S. (1992) Reasoning and the Logic of Things: The Cambridge Conferences Lectures of 1898, edited by K. L. Ketner, Harvard University Press, Cambridge, Massachusetts.

Peirce, C. S. (1998) "Pragmatism," in The Essential Peirce, volume 2, The Peirce Edition Project (Eds.), Indiana University Press, Bloomington and Indianapolis, Indiana.

Popper, K. R. (1996) The Open Society and Its Enemies, 5th edition, Princeton University Press, Princeton, New Jersey.

Popper, K. R. (1989) Conjectures and Refutations: The Growth of Scientific Knowledge, 5th edition, Routledge, London, England.

Porter, M. E. (1980) Competitive Strategy: Techniques for Analyzing Industries and Competitors, Free Press, New York.

Saabeel, W., Verduijn, T. M., Hagdorn, L. \& Kumar, K. (2002) "A model of virtual organization: A structure and process perspective," Electronic Journal of Organizational Virtualness (4:1), pp $1-16$.

Soros, G. (1998) “Toward a global open society,” The Atlantic Monthly (28:1), pp 20-32.

Sowa, J. F. (2000) Knowledge Representation: Logical, Philosophical, and Computational Foundations, Brooks/Cole, Pacific Grove, California.

Supply-Chain Council. (2000) Supply-Chain Operations Reference-model: Overview Version 4.0.

Wand, Y., and Weber, R. (2002) Research commentary: Information systems and conceptual modeling - a research agenda. Information Systems Research (13:4), pp 363-276.

Whitehead, A. N. (1929) Process and Reality, corrected edition edited by D. R. Griffin and D. W. Sherburne, The Free Press, New York, 1978. 